13th Pacific-Rim Real Estate Society Conference

Fremantle, Western Australia, 21 to 24 January 2007

\title{
THE FUTURE @ WORK - DELIVERING EFFECTIVE CORPORATE REAL ESTATE
}

Clive M J Warren - University of Queensland

Julia Simmons - DEGW Asia-Pacific

Nick Trumble - CoreNet Global

Contact author for all inquiries:

Clive Warren. c.warren@uq.edu.au

\begin{abstract}
The changing nature of the workplace is clearly shown in this paper which undertakes a comprehensive survey of Corporate Real Estate executives in Australia. The survey establishes a benchmark of attitudes to the office as an enabler of business and will form the basis for ongoing evaluation of changing attitudes to workplace provision. The paper highlights an expected increase in the need for flexible working environments while discussing the need to deliver not only cost efficient workplaces but effective, productive work environments.
\end{abstract}




\section{Introduction}

The role of real property as an essential enabler of business has been recognised for several decades, and yet the information available to managers of those property assets is relatively sparse. The history of asset management within both the private and public sector has largely been one of moving from the notion of a free good in which property is not recognised, (Jones Lang Wootton Research 1991; Then 1998), to managing costs to ensure efficient delivery of supporting infrastructure, (Varcoe 2002). The models developed by Joroff et al (1993) to measure the stepwise progressive management of corporate real estate from taskmaster to business strategist has largely gone unnoticed by the boardrooms of our major corporations. This research project aims to address some of the information barriers that corporate real estate (CRE) managers face and to provide an ongoing measure of the health of the CRE industry in Australia. The Research was an initiative of CoreNet Global through its Australian and New Zealand Chapters and DEGW Asia-Pacific as research partners. It is recognised that previous time series surveys of CRE professionals were undertaken by Bon in Europe and North America (Bon 1998; Bon \& Luck 1999, 2000). They provided a picture of the developing CRE industry in those countries and highlighted the levels of CRE management and the changing nature of CRE professionals. This research seeks to build on this earlier work and develop an information base for Australia.

The corporate real estate profession globally has continued to develop with many organisations recognising the importance of sound strategic management of their property assets, yet research in a number of countries has shown that a significant proportion of our major corporations still fail to undertake even the basic levels of prudent asset management, a management approach which is leading to considerable loss in potential revenue savings to the organisation (Warren 2004). It is also becoming clear in the literature that a divide is emerging between the organisations that have minimal, if any, strategic planning of CRE and those that recognise the value of good management and, further more, are moving toward a recognition of the need to provide not just efficient property solutions but assets which enable business to function more effectively through increased productivity (Pinder et al. 2003; Warren 2006). This research paper attempts to 
establish a benchmark of Australian practice in CRE against which future trends can be measured.

\section{Survey Objectives}

This research project seeks to identify the key issues facing the CRE industry in Australia and to establish baseline date for the ongoing measurement of the developing profession. The research methodology was based around an online survey of CRE executives with an objective that the survey seeks to identify attitudes and opinions of key professionals rather than seeking specific quantification of performance measures. The survey was intended to take participates no more than 10 minutes to complete, with answers based on professional opinion and perceptions of the industry as a whole as well as their corporation in particular.

The survey questionnaire was developed in consultation with senior CRE practitioners in CoreNet Global and research partners DEGW Asia-Pacific. It comprised some 40 questions in two sections. Part A of the survey was designed to establish a background profile of the respondent, seeking to identify the type of organisation, its size both in terms of assets and employees and the role of the respondent within the company.

The second part, Part B, of the questionnaire addressed 9 key areas of practice ranging from the role of CRE and its influence within the organisation, to issues relating to space use. The respondents were asked their opinion on the extent to which CRE can influence the workplace and the level of such influence within their organisation. This linked to questions relating to policy development within the organisation and the promotion of effective workplace provision. Issues, including site location, flexible working practices and the role of corporate social responsibility in providing working environments were addressed. Finally the survey asked for a vision of the profession moving forward and how it might develop to better serve the organisation into the future.

The survey instrument utilised a mixture of open ended questions to identify organisational data and Likert scale tick boxes to establish attitudinal data. The questionnaire was distributed via the internet in October 2005; to corporate real estate executives and major service providers throughout Australia. The data collected has been analysed and is presented in the following series of graphs. It is to be recognised that this 
is the first of a planned series of similar survey instruments and, as such, only provides a starting point for future comparison. It does, however, provide an interesting initial viewpoint which can be compared to research undertaken in other world regions.

\section{Survey Results}

The survey was undertaken in October 2005 and a total of 65 valid responses were received. The background information on survey respondents shows a high level of CRE engagement. The respondents were from both practicing CRE executives (31\%) and service providers and consultants (58\%), Figure 1 . The majority, 64\%, worked in the commercial property sector with a further $25 \%$ coming from public sector organisations, giving the survey a majority of office based organisations as respondents. The target higher level executive respondent was achieved with 38\% at director level and a further $47 \%$ in managerial roles.

\section{Figure 1 Respondents Job Type}

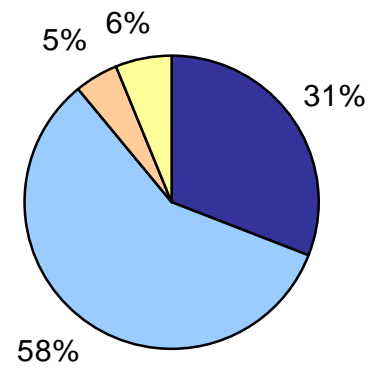

๑ Corporate End User

$\square$ Service provider/ Consultant

$\square$ Academic

$\square$ Other

The organisations represented tended to be large, with 51\% operating 10 or more properties within their portfolio and $86 \%$ occupying more than $5,000 \mathrm{~m}^{2}$ of space. The space occupied by $43 \%$ of those surveyed was greater than $50,000 \mathrm{~m}^{2}$. Thus the data represents practitioners and organisations at the higher end of the scale of organisations nationally. 


\section{Influence of CRE}

The role of CRE was explored seeking key professionals within the industries' attitude toward the effect which they and the profession can have on the delivery of workplace outcomes. The survey asked initially to what extent CRE professionals and the workplace can influence a series of eight key business drivers. Using a five point likert scale the results show that in 7 of the 8 business drivers over $55 \%$ said that CRE had a large influence Figure 2 -A. The highest rating factors, assistance in attraction and retention of staff, and support interaction and knowledge sharing among staff both had over $70 \%$ of respondents attributing CRE with a large influence. The second part to this question asked to what extent management in the respondent's own organisation saw CRE as contributing to these business drivers. The results of this second related question show a much lower level of influence across all 8 categories as shown in Figure 2-B.

Figure 2 CRE Influence on Business

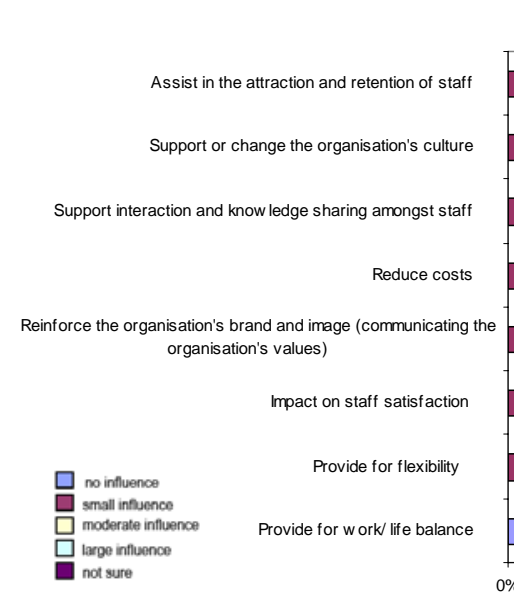

A: CRE Influence on Business Drivers

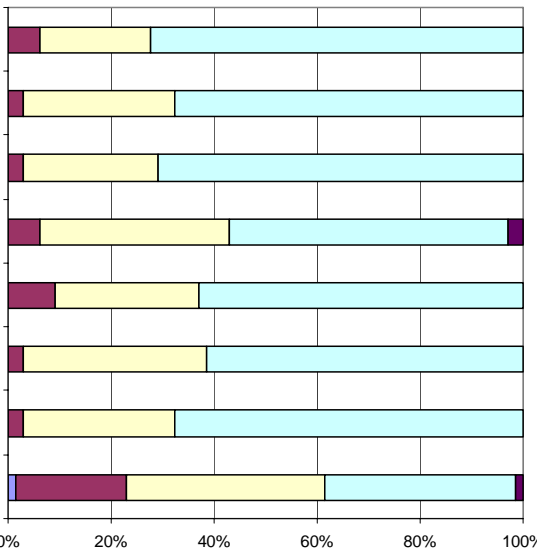

B: CRE Influence in own organisation

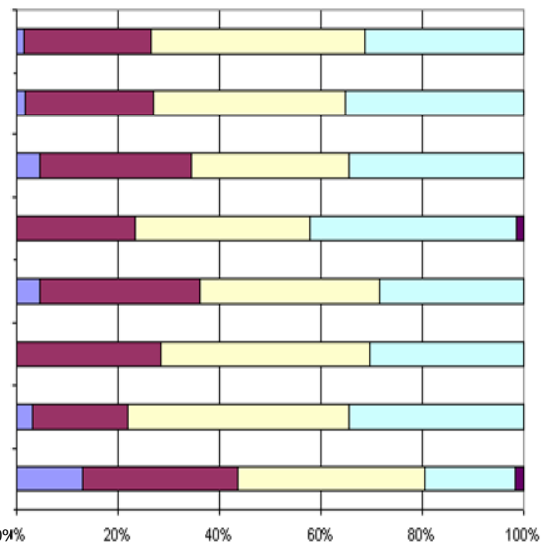

The difference in response clearly illustrates a mismatch between what CRE professionals believe the role to be in the management of the workplace and their perceptions of what management believe the role to be. The standout areas of attracting staff and sharing knowledge from the CRE professionals view point drop back substantially when viewed from a business management perspective. The issues identified as providing influence in the workplace were identified to be cost reduction 
and support for organisational cultural change. These latter measures clearly show a workplace strategy that is orientated toward efficiency through cost saving and implementation of physical change to reduce operating overheads rather than one which looks towards the positive aspects of workplace efficiency through staff satisfaction and knowledge dissemination.

Building on workplace drivers the survey sought to ascertain the role of CRE in workplace strategy. The results of this survey question illustrate the attitudes reflected in the previous question in that the strategic focus is more aligned with cost saving and organisational change management than it is with the workplace effectiveness measures of staff satisfaction and attracting and retaining staff. Figure 3 shows the largest influence of CRE to be in reducing costs, a traditional area with which business associates the role of property but not one that readily assists CRE professionals to provide a workplace which attracts and retains the best staff for the organisation or that adds value to the organisation through enhanced productivity.

Figure $3 \mathrm{CRE}$ and Workplace Strategy

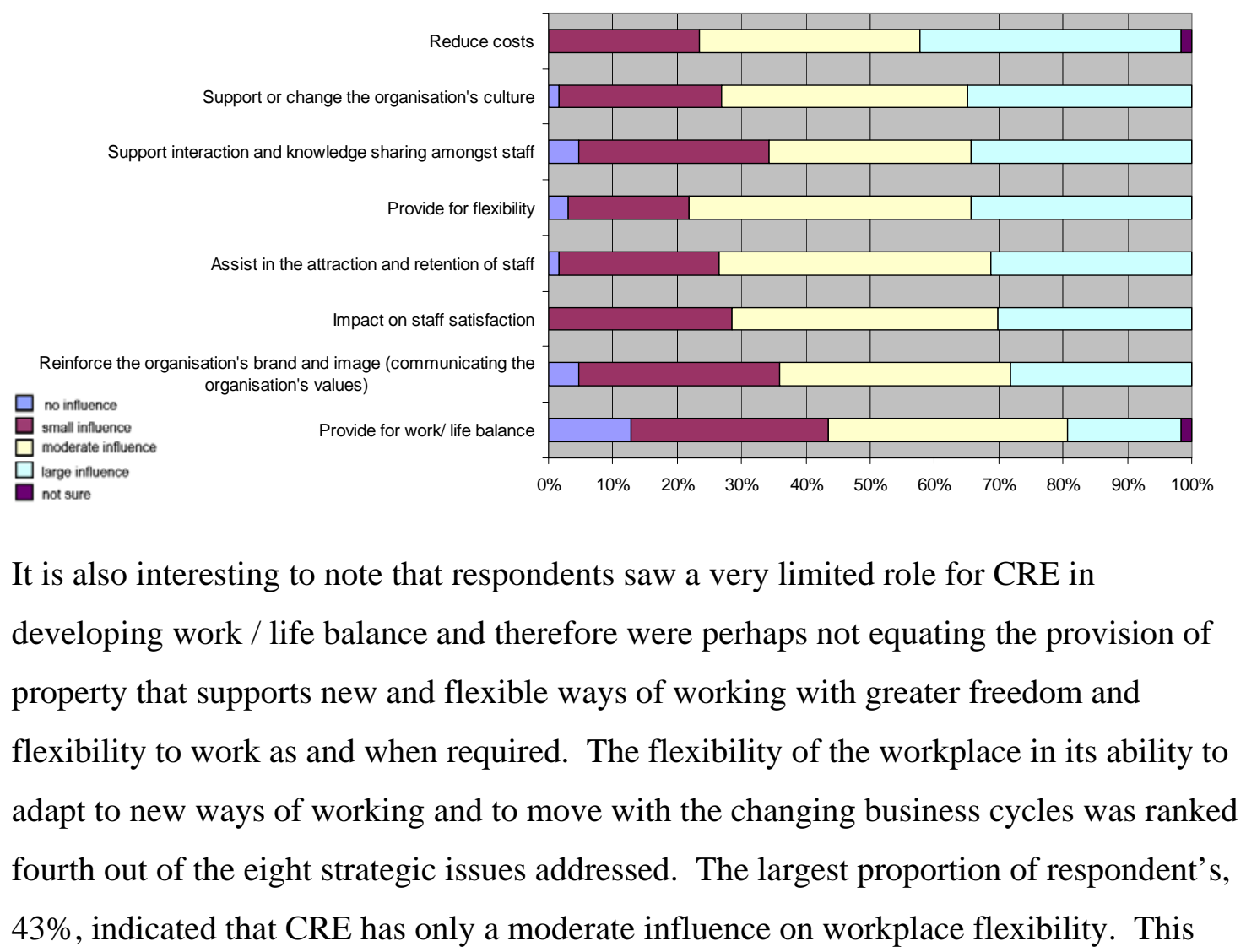


result can be compared with the result from a further question which sought to ascertain to what extent organisations would be prepared to pay a premium in their rent or acquisition costs to achieve flexible design and flexible contract terms for property. Figure 4 compares the results of this question which asked for the current situation and a projection for the organisations answer in 2010.

\section{Figure 4 CRE Flexibility}

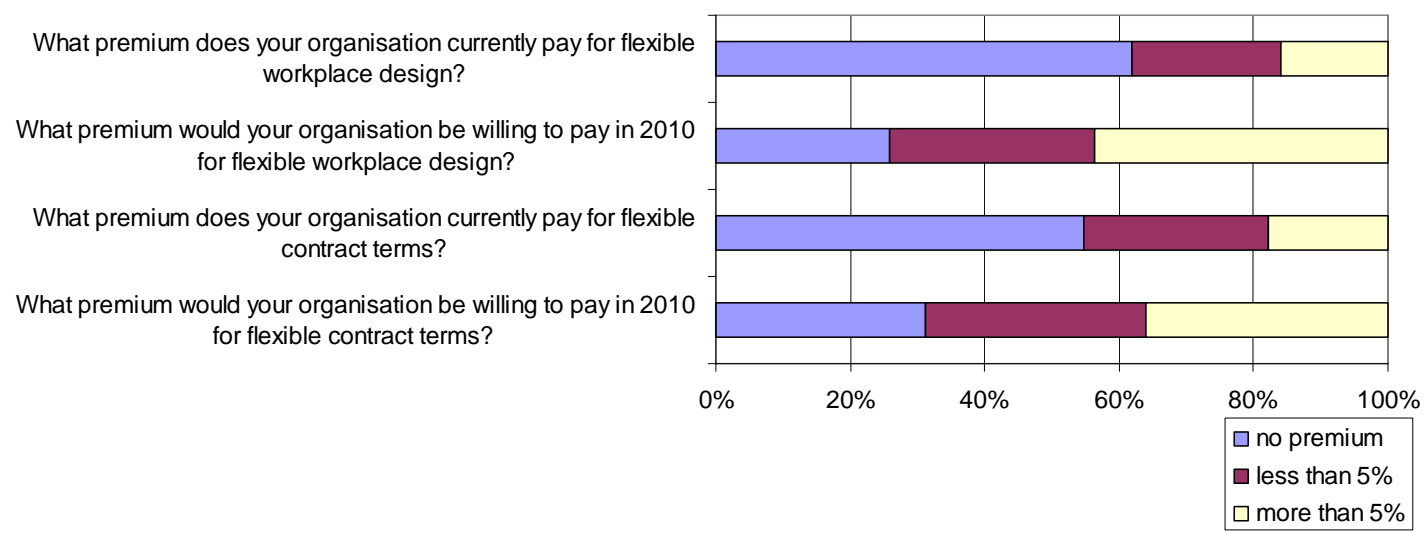

The survey shows that respondents expect the proportion of those prepared to pay a premium (in excess of 5\%) for flexible workplace design is predicted to jump in the next 5 years. Only $16 \%$ of respondents indicated that they would currently pay a premium greater than 5\% for flexible workplace design, but by 2010, this would more than double with $44 \%$ of respondents willing to pay a premium.

The survey results also indicated an increase in the number of people willing to pay more than $5 \%$ for flexible contract terms by 2010 . Those prepared to pay more than $5 \%$ would double, from $18 \%$ now to $36 \%$ in the future. Developers, building owners and their providers will surely be the greatest beneficiaries of this trend if they can deliver the flexibility that organisations are willing to pay for.

Flexibility of workplace design appears to be a slightly higher priority than flexible contract terms. This means that designers must increasingly ensure that they design space to be inherently flexible to adjust to changing organisational requirements over time and that CRE managers must also ensure that space is managed with flexibility in mind.

This apparent increasing desire for workplace flexibility is further illustrated in response to the survey in relation to changes in space use. Respondents were asked to assess how 
they saw their employees using workspace in 2010 compared with the current pattern of use. Figure 5 shows the survey results which indicate the greatest movements to be away from staff utilising their assigned space, where 55\% predict a decrease in space use. The movement, not surprisingly, is toward team based workspace with $61 \%$ predicting an increase and, of these, over half expect a large increase in team space working.

Figure 5 Changes in Space Use

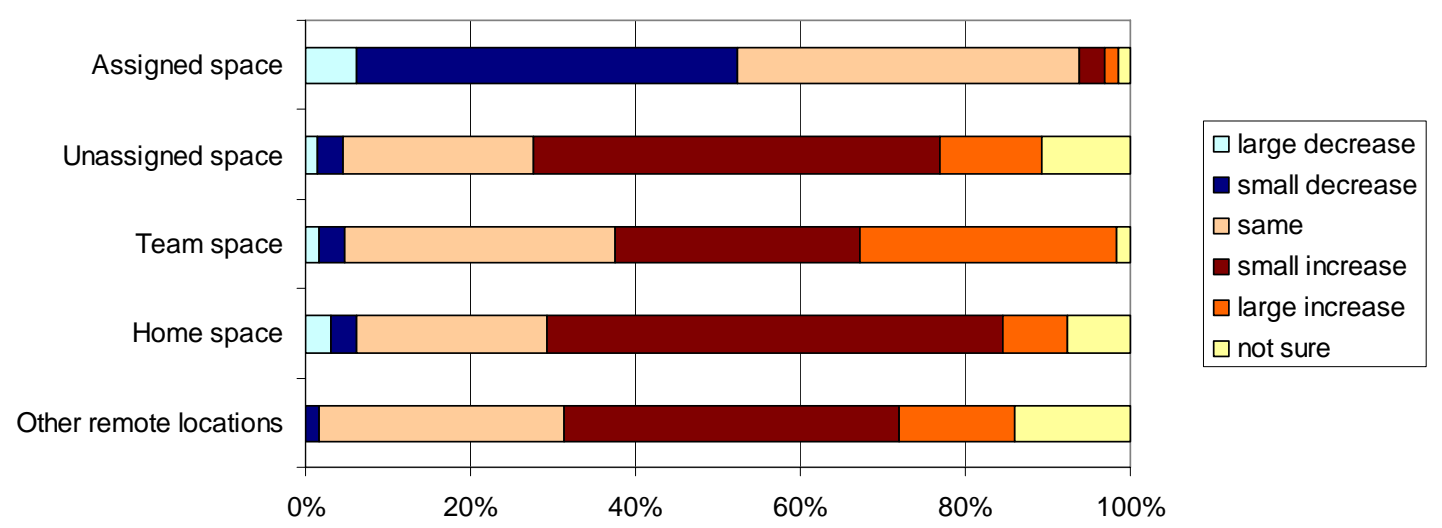

The other growth area for space use is in home space use with $65 \%$ of respondents expecting this to increase, although the majority, 56\%, only expect this to be a small increase. These results reflect the growing workplace trend toward project based working and equate well with the results in Figure 4 above which predict an increased demand for workplace flexibility and a willingness by employers to pay for this flexibility.

\section{Staff Mobility}

Along with workplace flexibility and the move towards a more team based approach to working, the role of employees within the corporation is perceived to be changing. To meet the needs of the flexible organisation it might be expected that employee flexibility and mobility might be a requirement of the future workplace. The survey sought attitudes to changes in the working practices of their employees and the level to which the organisation has formalised these practices. The majority of respondents, $86 \%$, indicated that their organisation would expect greater mobility of staff by 2010 . The mobility would occur both within and outside of the office environment, again linking to the expectation of flexible workplace design and the move toward team based working. 
The survey also revealed that currently $61 \%$ of respondents had home working as an employee mobility option. However, only $45 \%$ had established a formal policy for staff working from home. Respondents also indicated that only 34\% felt that they were appropriately informed of the legal and health and safety aspects of working from home. The number indicating that they lacked appropriate information was 58\%. It would appear that the rapid changes in workplace practice and the use of staff mobility, including home working has, occurred in a largely ad hoc arrangement within many organisations and the lack of formal structure may leave some organisations vulnerable to worker's compensation claims.

The growth of home working in organisations is most limited by the requirements of the job, with $75 \%$ of respondents citing this as a limiting factor, Figure 6 . Technical difficulties with IT and security were also significant limiting factors.

\section{Figure 6 Limitations on Home Working}

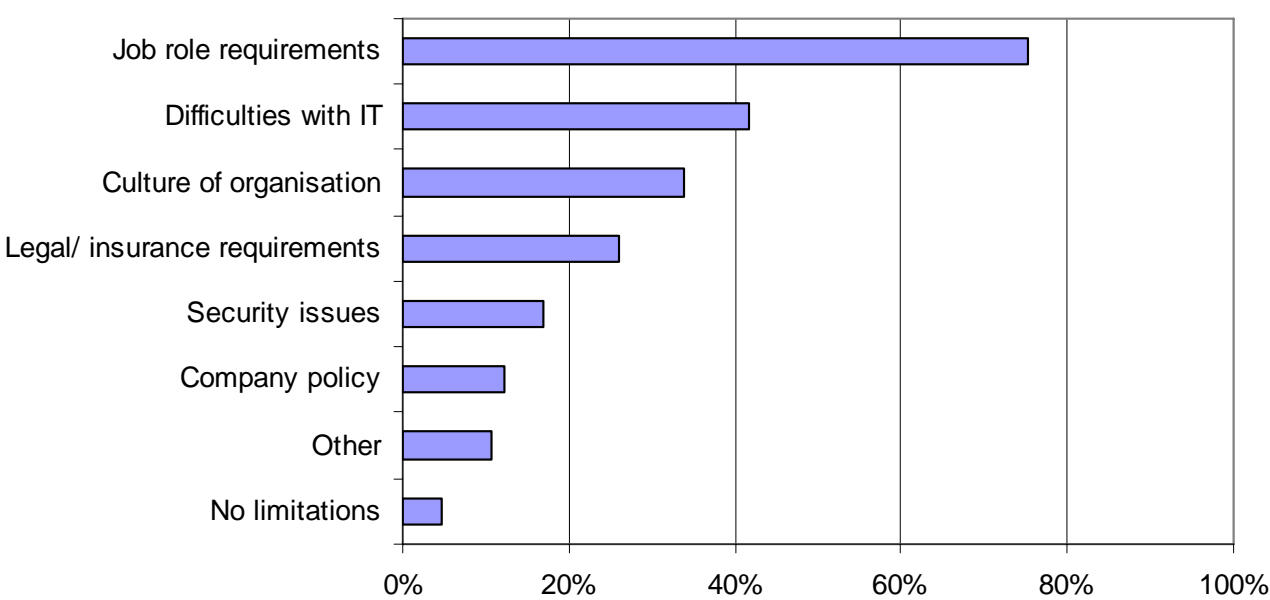

The culture of the organisation was seen by $34 \%$ as the factor limiting the growth of home working within their organisation and is indicative of the belief that increased home working within an organisation can reduce the level of communication between workers, particularly if formal and informal measures are not introduced to counteract the isolating influence that working from home brings. 


\section{Conclusion}

This survey, the first in what is expected to be a series of similar attitudinal surveys provides us with an insight into where industry practitioners see the CRE industry moving in the near future. Future iterations of the survey will provide a measure of how the attitudes of industry are changing over time, however, this survey provides a useful starting point against which to assess the use of corporate property in Australia and the attitudes of key executives in the industry.

The issues that have emerged from this research are perhaps not surprising. The CRE industry has developed to a stage where it is itself well established but has not, as yet, attained full recognition by the leadership of many corporations. This inevitably has resulted in a disconnect between the aspirations of CRE executives to facilitate effective workplace delivery which supports the growth of the organisation and senior management's expectations that CRE executives will deliver cost savings and an efficient workplace.

The changing nature of work will perhaps go some way to eliminating this division between effectiveness and efficiency in workplace design. As the survey shows, organisations are changing and expect to rapidly increase their level of flexibility, both in terms of the nature of the space they occupy and the terms under which they occupy the space. Flexibility translates into new working practices with much increased project based delivery of work and greater freedom, where appropriate, to work away from the owned individual workpoint, whether elsewhere in the office or from home. These changes bring with them additional problems for CRE executives in delivering a workplace which enables easy mobility of staff into team based work environments while at the same time supports staff working from other locations than the office without an over provision of workstations. This brings to the fore issues of workstation hotdesking and other related practices to increase the efficiency of the office design.

One thing is certain from the survey, the pace of workplace strategic change will continue at a pace with new technological changes and working practices requiring CRE executives to continue to adapt the work environment to support the business objectives of the organisation and to deliver effective workplace design. Increased integration of 
workplace enabling functions, including information technology and human resource management, is a likely outcome of these changes.

\section{Bibliography}

Bon, R 1998, 'Annual CREMRU-JCI survey of corporate estate management practices in Europe and North America: 1993-1997', Facilities, vol. 16, no. 3/4, pp. 82-92.

Bon, R \& Luck, R 1999, 'Annual CREMRU-JCI survey of corporate real estate practices in Europe and North America 1993-1998', Facilities, vol. 17, no. 5/6, pp. 167-76. ---- 2000, 'Annual CREMRU-JCI survey of corporate real estate in Europe and North America: 1993-1999', Facilities, vol. 18, no. 5/6, pp. 213-24.

Jones Lang Wootton Research 1991, 'Managing operational property assets', vol. JLW.

Joroff, M, Louargand, M \& Lambert, S 1993, Strategic management of the fifth resource - Corporate real estate, IDRC -Industrial Development Research Council.

Pinder, J, Price, I, Wilkinson, SJ \& Demack, S 2003, 'A method for evaluating workplace utility', Property Management, vol. 21, no. 4, pp. 218-29.

Then, DS-S 1998, A model for considering operational property as an enabling resource to business, RICS Research.

Varcoe, BJ 2002, 'The performance measurement of corporate real estate portfolio management', Journal of Facilities Management, vol. 1, no. 2, pp. 117-30.

Warren, CMJ 2004, 'Property in business - Inefficiencies in corporate property investment in Australia', paper presented to CIB/CRC for Construction Innovation - Clients Driving Innovation International Conference, Gold Coast, Australia, 25 28 October,.

---- 2006, 'Strategic Asset Management and the Evaluation of Office Workplace Utility', paper presented to AsRES - AREUEA Joint International Conference, Vancouver, Canada, 30 June - 3 July 2006. 